Marquette University

e-Publications@Marquette

Mathematics, Statistics and Computer Science

Mathematics, Statistics and Computer Science,

Faculty Research and Publications

Department of

5-1-2018

\title{
Preservice Mathematics Teachers' Conceptions and Enactments of Modeling Standards
}

Hyunyi Jung

Marquette University, hyunyi.jung@marquette.edu

Jill Newton

Purdue University

Accepted version. School Science and Mathematics, Vol. 118, No. 5 (May 2018): 169-178. DOI. (C)

2018 Wiley. Used with permission. 
Marquette University

\section{e-Publications@Marquette}

\section{Mathematics, Statistics and Computer Science Faculty Research and Publications/Department of Mathematics, Statistics and Computer Science}

This paper is NOT THE PUBLISHED VERSION; but the author's final, peer-reviewed manuscript. The published version may be accessed by following the link in the citation below.

School Science and Mathematics, Vol. 118, No. 5 (May 2018): 169-178. DOI. This article is (C) Wiley and permission has been granted for this version to appear in ePublications@Marquette. Wiley does not grant permission for this article to be further copied/distributed or hosted elsewhere without the express permission from Wiley.

\section{Preservice Mathematics Teachers' Conceptions and Enactments of Modeling Standards}

Hyunyi Jung

Marquette University

Jill A. Newton

Purdue University

\section{Abstract}

Mathematical modeling has been highlighted recently as Common Core State Standards for Mathematics [CCSSM] included Model with Mathematics as one of the Standards for Mathematical Practices [SMP] and a modeling strand in the high school standards. This common aspect of standards across most states in the U.S. intended by CCSSM authors and policy makers seems to mitigate the diverse notions of mathematical modeling. When we observed secondary mathematics preservice 
teachers [PSTs] who learned about the SMP and used CCSSM modeling standards to plan and enact lessons, however, we noted differences in their interpretations and enactments of the standards, despite their attendance in the same course sections during a teacher preparation program. This result led us to investigate the ways the PSTs understood modeling standards, which could provide insights into better preparing teachers to teach mathematical modeling. We present the contrasting ways in which PSTs presented modeling related to their conceptions of mathematical modeling, choices of problems, and enactments over an academic year, connecting their practices to extant research. We consider this teaching and research experience as an opportunity to make significant changes in our instruction that may result in our students enhanced implementation of mathematical modeling.

Policy documents and research studies in mathematics education support an emphasis on students' learning about modeling (e.g., National Council of Teachers of Mathematics [NCTM], 2000; Lesh \& Lehrer, 2003). Students can develop their problem solving abilities by engaging with modeling activities that provide opportunities for them to recognize mathematics as being useful beyond school (Lesh \& Lehrer, 2003). Modeling was also emphasized by the authors of Common Core State Standards for Mathematics (CCSSM); they recommended that teachers promote students' deeper understanding of mathematics through modeling (National Governor's Association Center for Best Practices [NGA] \& Council of Chief State School Officers [CCSSO], 2010). It is beneficial for teachers to consider modeling as a process that involves both real-life and mathematical problem solving, including the selection of variables that represent the context, formulation of representational descriptions, analysis of the model to find solutions, interpretation and validation of the solutions, and reporting the results (e.g., Blum \& Niss, 1991; Gravemeijer, 2004; NGA \& CCSSO, 2010).

Although researchers and professional organizations have emphasized the importance of modeling, "there is no single agreed-upon definition of mathematical modeling; instead there are definitions or descriptions put forth by individual authors or assumptions of shared understandings" (Cirillo, Pelesko, Felton-Koestler \& Rubel, 2016, p. 8). There are also a variety of principles to choose from when designing problems that engage students with mathematical modeling, including principles for designing model-eliciting activities [MEAs] (Lesh, Hoover, Hole, Kelly \& Post, 2000) or principles for 
designing modeling problems (e.g., Galbraith, 2007). Since the authors of CCSSM included Model with Mathematics as one of the Standards for Mathematical Practice (SMPs), mathematical modeling described in the SMP has been widely used in U.S. education research and practice (e.g., Jung, Mintos, \& Newton, 2015; Bostic \& Matney, 2014). This common aspect of standards across most states in the U.S. intended by CCSSM authors and policy makers seems to mitigate such a diverse notion of mathematical modeling. When we observed secondary mathematics preservice teachers [M-PSTs] who learned about SMPs and used CCSSM modeling standards to plan and implement lessons, however, we noted differences in their interpretations of the standards, despite their attendance in the same course sections during a teacher preparation program. This result led us to investigate the ways the M-PSTs understood modeling standards differently, which could provide insights into better preparing teachers to teach mathematical modeling. Specifically, we focused on the question, "How do M-PSTs conceptualize and enact mathematical modeling standards?" As we focus on this question related to mathematical modeling standards, we review previous and current standards related to modeling and opportunities to learn about mathematical modeling in teacher preparation in the following sections.

\section{Curricular Recommendations and Standards Related to Models and Modeling}

NCTM (1980) published An Agenda for Action, which highlighted the use of graphic models and simulations of realistic situations, and provided suggestions for college level courses to give M-PSTs opportunities to engage with modeling and problem solving. Expanding upon these recommendations, NCTM's (1989) Standards further addressed mathematical modeling, recommending that K-12 students have opportunities to understand mathematical models applicable to many other disciplines, such as engineering and physical science.

NCTM (2000) included several standards stating the importance of models and modeling. The algebra standard recommended that all students have opportunities to use models to represent 
quantitative relationships. The geometry standard also addressed modeling, recommending that PK-12 students should use geometric modeling and spatial reasoning to solve problems. In 2009, NCTM published its first document specifically centered on high school mathematics, Focus in High School Mathematics: Reasoning and Sense Making. This document described benefits resulting from students' engagement in mathematical modeling, including connecting mathematical concepts, building mathematical reasoning, and developing application abilities.

In CCSSM (NGA \& CCSSO, 2010), adopted by the vast majority of states, "Model with mathematics" is one of the Standards for Mathematical Practice recommended for all students; it recommends that students use mathematics for everyday problem solving. In addition, the CCSSM high school standards include expectations that students have opportunities to be engaged with the modeling cycle described in the standards (i.e., identify variables, formulate a model, perform operations, interpret the results, validate the conclusions, and report on the conclusions) (NGA \& CCSSO, 2010). The standards' increasing emphasis on mathematical modeling necessitates professional development and preparation for teachers to learn about effective ways to teach mathematical modeling to their students.

\section{Opportunities to Learn about Modeling in Teacher Education}

Although the relatively new CCSSM requires that teachers teach mathematical modeling, many have not experienced mathematical modeling as learners (Phillips, 2016). In a study of investigating opportunities to learn about modeling in teacher preparation programs (Jung, Mintos, \& Newton, 2015), 16 course instructors and 11 M-PSTs in three teacher preparation programs were interviewed about the learning opportunities they had related to CCSSM's modeling cycle. Most of the interviewees reported opportunities related to a few components of the modeling cycle, but not the modeling cycle in its entirety. Garfunkel et al. (2016) presented Guidelines for the Assessment and Instruction in Mathematical Modeling Education [GAIMME] report as a way to give opportunities for teachers to learn 
how to engage students in mathematical modeling by providing modeling tasks. The GAIMME report also described a variety of ways in which teachers can incorporate mathematical modeling into their practice, along with the integration of assessment tasks and other resources for teaching modeling to K16 students.

Other researchers have investigated the knowledge and practices necessary to effectively teach mathematical modeling. Zbiek (2016) emphasized that teachers need opportunities to discuss their conceptions of mathematical modeling, recognize the key aspects of modeling as a process, and use modeling to support students' learning of mathematical content. As teachers learn about modeling, they need activities (e.g., Model-Eliciting Activity or MEA) that allow them to connect their mathematical understanding to problem scenarios and utilize a range of representations (Doerr, 2016). M-PSTs would also benefit from modeling knowledge that can be used in the classroom; for example, teaching and revising lessons based on the analysis of student learning in class (Hiebert, Morris, Berk, \& Jansen, 2007). Several ideas mentioned in this paragraph were incorporated into the M-PSTs' coursework that served as the setting for this study. For example, the M-PSTs discussed the conceptions of mathematical modeling as a process (Zbiek, 2016), connected their mathematical understanding to the problem scenario of the Big Foot MEA (Doerr, 2016; Lesh \& Harel, 2003), and were required to connect coursework with their teaching practice by implementing several lesson plans and analyzing student learning (Hiebert et al., 2007). We further describe these incorporations after describing our theoretical framework.

\section{Theoretical Framework}

Drawing on extant research and standards related to mathematical modeling, along with the connections to our data, we used a theoretical framework for distinguishing between mathematical modeling and modeling mathematics, as well as selecting and designing problems related to mathematical modeling. We also found examples from our data in which M-PSTs used modeling 
standards to teach mathematics closely related to the notion of teaching mathematics for or via problem solving (Schroeder \& Lester, 1989). Accordingly, we describe these terms associated with mathematical modeling.

\section{Mathematical Modeling vs. Modeling Mathematics}

Researchers have described mathematical modeling as a process that contains components of both real-life and mathematical situations (Blum \& Niss, 1991; Gravemeijer, 2004; Lesh \& Harel, 2003; Lesh \& Lehrer, 2003). According to Gravemeijer (2004), for example, mathematical modeling is defined as "translating a real-world problem into mathematics, working the math, validating the results, and translating the results back into the real-world context" (p. 3). Mathematical modeling also involves an iterative process of interpreting a situation, constructing representational descriptions, and developing through revision cycles (Lesh \& Lehrer, 2003). On the other hand, modeling mathematics is often interpreted as the use of tools, such as concrete objects, physical, or virtual manipulatives, to represent mathematics (Cirillo et al., 2016). The distinction between mathematical modeling and modeling mathematics is often not made clear in research and standards documents, including CCSSM, which uses both terms without clarifying the meanings (Cirillo et al., 2016).

\section{Potential Interpretations of Modeling Problems}

Another possible distinction that causes some confusion is the differences between modeling problems and word problems. Although a modeling problem is distinguished from a "dressed-up" word problem (Schukajlow et al., 2012) or a story problem (Blum \& Niss, 1991), these two types of problems are similar in terms of the real-life connections often embedded in the problems (Schukajlow et al.). One of the reported differences between these two types of problems is that a real-world situation in a word problem is often much simpler than a modeling problem, as all the data needed to find the solution are usually supplied by the word problem (Schukajlow et al.). In modeling problems, students are more likely to face cognitive barriers as they make assumptions about the findings or select relevant data from 
the context (e.g., Blum, 2011). Students may also face increased difficulty with validating the results of the modeling problem compared to those solving word problems (Schukajlow et al.).

In terms of developing modeling problems, researchers have presented several principles to guide the development. Lesh et al. (2000) offered six principles for designing modeling problems (i.e., model construction, reality, self-assessment, construct documentation, shareability, reusability, effective prototype). They provided an MEA as an example of modeling problems that meet all six principles. In an MEA, teams of students engage with simulations of real world problem-solving that requires them to mathematize the situation. Galbraith (2007) also offered principles for modeling problem design, which included five principles (i.e., genuine links to the real world, mathematical questions driven from the problem, feasible solution process, mathematical interpretation, evaluation) and a didactical design principle. Their frameworks are closely related, but also notably different; for example, Galbraith's principles featured the didactical design principle proposing that the problem be structured into sequential questions, which was not addressed by Lesh and his colleagues (2000). Another difference is the design of the sharable and reusable problem (Lesh et al., 2000), which is not included in Galbraith's principles. Galbraith and Lesh et al. noted that there were not many mathematical modeling problems in textbooks that satisfied either set of principles. Although modeling problems based on these frameworks have since been developed, it is not surprising that there have been disagreements about what qualifies as a modeling problem given the existence of different design principles.

\section{Teaching Mathematics for Problem Solving vs. via Problem Solving}

Mathematical modeling is closely related to problem solving as one needs to solve problems when they are engaged with mathematical modeling (e.g., Lesh \& Harel, 2003 \& Lester \& Kehle, 2003). Schroeder and Lester (1989) described approaches to problem-solving instruction that includes teaching mathematics for or via problem solving. Teachers who teach for problem solving tend to save problem solving for after students have learned all the related mathematical concepts. In this conceptualization, 
the purpose for problem solving is to provide students with an opportunity to develop a computational skill or to solve sample story problems to apply the concepts they have learned. When teaching via problem solving, teachers value problem solving not only as necessary to learn mathematics, but also as a primary purpose in and of itself. Those who ascribe to this conceptualization content that teaching mathematics starts with a problem context that includes key aspects of mathematical topics. In this case, the purpose of problem solving is to provide students with an opportunity to engage with the concrete (e.g., a real-world problem) and move to the abstract (e.g., a symbolic representation or technique to operate on representations) (Schroeder \& Lester, 1989).

\section{Connecting Research to Practice in the Context of a Teacher Preparation Program}

Building on the researchers' work described in the previous theoretical framework section (e.g., Cirillo et al., 2016; Schroeder \& Lester, 1989; Schukajlow et al., 2012), we examined how the conceptualizations, perspectives, and instructional approaches discussed in extant research and policy documents can relate to practice in the context of a teacher preparation program. This section describes the background of the study and data collected from three consecutive courses over an academic year, and reflects on M-PSTs' perspectives and enactments related to mathematical modeling.

\section{Background of the Study}

The secondary teacher preparation program which serves as the setting for this study, located in a midwestern university in the U.S., required three consecutive mathematics education courses that involve field experiences. The first and third courses were taught by the first author; the second course was co-taught by both authors. For all three courses, we regularly met to discuss our course design, content, and M-PSTs' learning while we documented our lesson plans for each course session. Class lessons generally utilized small-group problem solving and discussions followed by instructor-led, whole- 
class discussions. M-PSTs (18 in total) also had opportunities to provide peer feedback on the other groups' work, including lesson plans and assignments, prior to final submission.

The first course focused on developing an overall vision for and understanding of teaching high school mathematics using Principles and Standards for School Mathematics (NCTM, 2000) and CCSSM (NGA \& CCSSO, 2010). Each session was focused on a major theme of these documents, including equity, curriculum, assessment, technology, problem solving, representations, and the eight SMPs. Mathematical modeling served as a session theme of the first methods course. As the instructor of the session, the first author provided opportunities for M-PSTs to learn about current modeling standards, engage with mathematical modeling as a learner, and identify modeling problems in textbooks in order for them to revisit their definitions of mathematical modeling. First, M-PSTs were asked to read SMP: Model with Mathematics (NGA \& CCSSO, 2010); and then they individually wrote their answer to the question, "What's your definition of mathematical modeling?" Next, they participated in the "Big Foot" MEA (Lesh \& Harel, 2003) in teams of three or four and presented their solutions to the whole class. This MEA was selected because it contains an authentic problem-solving situation (i.e., finding culprit's height when given his footprints) that requires students to develop and use mathematical models. They then revisited their own definitions of mathematical modeling and discussed the modeling standards described in CCSSM. During this discussion, they were asked to find modeling problems from textbooks and share which aspects of the problems they considered as part of the modeling cycle. Finally, they individually wrote down their answer to the same question, "What is your definition of modeling?" without looking at the standards. M-PSTs also developed several lesson plans and a unit lesson plan in the first methods course.

The second methods course was designed for M-PSTs to learn about teaching in middle school mathematics classrooms. This course was also organized by topics, including worthwhile mathematical tasks, mathematical discourse, learning environments, analysis of teaching and learning, and assessment 
(NCTM, 1991). M-PSTs developed lesson plans, observed cooperating teachers and taught lessons in the field, and submitted a weekly journal reflection. The third course was a 10-week seminar experience that accompanied student teaching. In the seminar, the M-PSTs engaged with a series of speakers about topics important to teaching secondary mathematics (e.g., students with special needs, supporting LGBTQ students) and developed a portfolio that included assignments focused on analyzing student learning and lesson planning. M-PSTs student taught for 10 weeks in a cooperating teacher's classroom under the guidance of a university supervisor. They set their student teaching goals on the first day of the course and developed lesson plans that would be used during their student teaching. The university supervisors observed the M-PSTs at least five times during this field experience.

\section{Data Sources and Analysis}

After M-PSTs completed all three courses, we collected their written definitions of mathematical modeling from the first methods course, lesson plans from all three courses, and their reflections on student teaching and university supervisors' observation forms. The authors' lesson plans and notes also served as data for the study. Data sources were analyzed using the theoretical framework focused on mathematical modeling vs. modeling mathematics, potential interpretations of modeling problems, and teaching mathematics for or via problem solving.

First, 18 M-PSTs' definitions of modeling documented in the first methods course were examined for alignment with extant definitions of mathematical modeling and modeling mathematics. Each pre- and post-written responses was organized in an excel sheet and coded for whether it focused more on real-life problem solving process (closer to the meaning of mathematical modeling) or the use of representations or manipulatives (closer to the meaning of modeling mathematics). This informal analysis was originally used as a formative assessment for the instructors to gain insights into the extent to which M-PSTs changed their conceptualizations of mathematical modeling after engaging with modeling activities we planned and implemented. We revisited the coded data in the excel sheet to 
verify the original codes that aligned with the distinction between mathematical modeling and modeling mathematics.

Second, the student teaching goals and problems included in the $18 \mathrm{M}-\mathrm{PST} \mathrm{s}^{\prime}$ lesson plans were reviewed to examine to what extent they incorporated mathematical modeling in their lesson plans and during their student teaching. Among several M-PSTs who included real-life connections to mathematics as a student teaching goal but did not incorporate CCSSM modeling standards into their lesson plans, we found two M-PSTs (Pseudonyms: Ava and Zoe) who not only included such student teaching goal, but also incorporated several modeling standards into their lesson plans. These two M-PSTs also presented different types of real-life problems in their lesson plans and showed distinct ways of implementing their problems, which captured an example of contrasting cases (Yin, 2014). Their lesson plans were organized in a table in which each row included the modeling standards, goals for the lesson, mathematical problems, implementation plans, university supervisor's notes, and M-PSTs' reflections for each of them. This table was used to describe and summarize the elements based on our framework that focused on the potential varied interpretations of modeling problems.

Last, the table described above was also used to investigate the ways in which Ava and Zoe incorporated modeling standards into practice focusing on teaching mathematics for or via problem solving. For member checking (Yin, 2014), Zoe and Ava were given the opportunity to review and suggest revisions to the original tables. Their revisions were all accepted and rearranged in subsequent sections without changing their contents.

\section{M-PSTs' Definitions: Modeling Mathematics vs. Mathematical Modeling}

In order to informally assess M-PSTs' learning of mathematical modeling, we investigated the definitions of modeling they wrote before and after the modeling session of the first methods course. Most of their modeling definitions (14 out of 18 responses) before engaging with modeling were close to the meaning of modeling mathematics (Cirillo et al., 2016), in which M-PSTs focused on the use of 
representations or manipulatives to represent mathematics without considering real-life contexts. For example, one M-PST wrote, "Modeling is a different way of showing mathematical representations such as using objects to solve a problem." Only four M-PSTs' definitions referenced the real-world; for example, an M-PST stated, "Mathematical modeling is using math to understand or define a real world situation."

When the same question was asked after the modeling session, more (10) M-PSTs' definitions were close to mathematical modeling (e.g., "Mathematically proficient student's ability to apply their math knowledge to real world problems. They must approximate, interpret, analyze, and evaluate their process, information, content, and results"). Four M-PSTs' definitions included modeling processes without mentioning a real-world context (e.g., "Given a problem you find a way to solve the problem or organize the data and you may need to revise your first effort or first try before you get the final product or method that works"). Four M-PSTs' definitions were still close to modeling mathematics, but included more details (e.g., "Different representations of mathematical concepts. Getting students to formulate ideas and interpret them").

Although not all M-PSTs adopted the previous research definitions of mathematical modeling (e.g., Gravemeijer, 2004; Lesh \& Lehrer, 2003), it was promising that several M-PSTs changed their view of mathematical modeling after only one course session focused on mathematical modeling. As the MPSTs progressed through their teacher preparation program, we considered "How do they enact what they learned about mathematical modeling into their practice?"

\section{Tracing M-PSTs' Lessons Related to Mathematical Modeling}

To answer the question above, we looked for any evidence of mathematical modeling in the $\mathrm{M}$ PSTs' lesson plans developed during the teacher preparation program. M-PSTs planned and implemented many interesting lessons to engage their students with rich mathematical concepts; however, we rarely found any modeling problems that satisfied the principles of designing modeling 
problems developed by researchers (e.g., Galbraith, 2007; Lesh et al., 2000), even when they used modeling standards from CCSSM. Therefore, we adjusted our attention from "How did they enact mathematical modeling" to "How did they use modeling standards to teach mathematics?" Distinct from 16 M-PSTs who rarely included CCSSM modeling standards in their lesson plans, two M-PSTs (Ava and Zoe) included modeling standards in at least one or two lessons in each course and student teaching, and aimed for their students to engage with connections between mathematics and real-life. When we examined lesson plans written by Ava and Zoe, we noticed the different nature of the problems they included to address CCSSM modeling standards, as described in the following section.

\section{Word Problems vs. Realistic Problems That Involve Problem Solving \\ The first modeling standard that appeared in Zoe's unit lesson plan was “A-CED.3 (CCSSM):}

Represent constraints by equations or inequalities, and by systems of equations and/or inequalities, and interpret solutions as viable or nonviable options in a modeling context $\left({ }^{*}\right)^{1 \prime \prime}$ (NGA \& CCSSO, 2010, p. 3). Zoe included five word problems for the final day of her unit lesson plan in her first methods course. She aimed for students to learn about "how quadratic equations can be used to model real life situations via word problems." To address this objective, Zoe planned to pass out a worksheet including a problem that required students to find the time when a baseball will be 48 feet above the ground or hit the ground, given the equations $s=-16 t^{2}+64 t$ ( $\mathrm{s}=$ the number of feet above the ground, $\mathrm{t}=\mathrm{seconds}$, initial speed of the baseball $=64 \mathrm{ft} / \mathrm{sec}$ ) (Swokowski \& Cole, 2011). This word problem may require students to model mathematics by drawing pictures or graphs, but students will likely not engage with mathematical modeling because the variables and formula are provided in the problem statement.

Ava also included a modeling standard in her unit lesson plan: "F-BF. 1a Write a function that describes a relationship between two quantities. Determine an explicit expression, a recursive process,

\footnotetext{
${ }^{1}$ This standard is in a cluster indicated by an asterisk $(*)$, which indicates that this is a modeling standard in the CCSSM high school standards.
} 
or steps for calculation from a context. $(*) . "$ She aimed for students to "model a problem using a graph and/or function," "get an intuitive understanding of how exponential functions behave," and "recognize an exponential function in graph form or algebraic form." Ava selected the following problem to achieve these lesson objectives:

There's a legend that the inventor of chess showed his invention to the ruler of his country, and the ruler liked the game so much he told the inventor he could have anything he asked for. The inventor said that for the first square of the chessboard he would like one grain of rice, two for the second one, four for the third, eight for the fourth, and so on. The ruler thought that this was a very low price to pay for, and quickly agreed. How much rice did the ruler agree to give the inventor for the game of chess? (Gamow, 2012).

Ava planned to start the lesson by showing students a short video and asking questions including, "How many squares are there on a chessboard?" and "What are the numbers and letters on the side of the chessboard for?" She did not intend to explain answers to these questions until she heard from her students. She noted the importance of students having frustration during problem solving: "Try not to give away too much of the problem-solving process, since you are trying to promote this skill in the lesson." Once students found a function and graphed it, Ava planned to "ask them what the function is and what it would look like." Through this process, she wanted to introduce the general form of the exponential function. After students came up with their own solution, she planned to "ask for volunteers to share their solutions with the class, including the method and the answer, and allow students to ask questions of their classmates."

Although this problem does not meet all the design principles of modeling problems, such as shareable and reusable principles (Lesh et al., 2000), it does involve several important modeling processes with which students could engage, including: (1) the application of "the mathematics they know to solve problems arising in everyday life," (2) the identification of "important quantities in a 
practical situation," (3) the mapping of "their relationships using such tools" as graphs, and (4) the analysis of "those relationships mathematically to draw conclusions" (NGA \& CCSSO, 2010).

Ava incorporated the identical mathematical structure (i.e., exponential growth) of this lesson plan during her student teaching. She reflected in her student teaching journal:

I gave them a bonus question that asked whether they would rather have \$1 million a day for every day in December, or \$1 on the first day, \$2 on the second day, then \$4, then $\$ 8$, and so on. When we reviewed the test, I asked them why they think I put this question on the test. No one talked about exponentials. I related it back to the first activity we did in this chapter which was about folding paper and how many sections you had each time you folded it. There was a bit of an "aha" moment when they saw how it related, but I'm still not sure whether they really got it...I need to do a better job helping them make connections and really exploring the concept, so it comes together for them so how.

Ava recognized the identical mathematical model in different real-life situations (Simon, 1995). She seemed to feel frustrated that students did not transfer their exponential growth concept to the successive problem and was critical of her enactment.

\section{Enactments: Teaching Mathematics for Problem Solving vs. via Problem Solving} The nature of problems included in the other lesson plans were similar to problems described above when Ava and Zoe included modeling standards in their student teaching lessons. In one student teaching lesson plan, Zoe included a CCSSM modeling standard: "Use proportional relationships to solve multistep ratio and percent problems (e.g., simple interest) $\left(^{*}\right)$ (7. RP. 3)" and aimed for students to "learn the formula to calculate simple interest and discover how to calculate the interest" [Lesson Plan]. Zoe included several word problems in her lesson plan, including a problem about opening an account, asking how much interest students would earn after 36 months if they deposited $\$ 3,000$ into their account with $6 \%$ simple interest. Zoe's supervisor described how the lesson was enacted in the seventh grade classroom: 
Students were briefly asked questions about interest [e.g., "What kinds of things in real life have interest?"]. Students were handed out a simple interest activity worksheet which began with the three vocabulary words (i.e., interest, simple interest, principal) needed for this lesson. The three vocabulary words were defined. The formula l=Prt was then given and each letter was identified with the appropriate word. Following the definition students were given two simple interest problems to solve in groups of two.

When Zoe reflected on this lesson, she felt that students did not develop their problem solving ability. She stated,

The students asked a lot of questions and did not apply as much problem solving skills as I would have liked. The students were not used to the explore part of the lesson where they had to use their problem solving skills to figure out how to do the problem and were quickly raising their hands to ask for assistance.

Students' questions focused on identifying the meanings of variables and understanding the formula introduced by the teacher. She continued, "When I introduced the formula for interest I=Prt, they did not know that $P, r$, and t were multiplied." Another difficult skill for students was solving for unknown variables. Zoe described what operations students had difficulty with when they were given the equation.

The students were also confused on how to solve for $P, r$, or $t$ when you are given the other three. Since it is not straight multiplication it was difficult to build up the idea that you divide by the two you were given by the interest so that you solve for your unknown. It seems really hard for them to figure that out.

Even though this task addressed the important life skill of opening a saving account, students did not apply problem solving abilities when they were introduced to the formula. In the teacher's eyes, the formula (I=Prt) might look simple, but students were unsure that $P, r$, and t were multiplied. They did not have the opportunity to understand how these variables were combined to make a formula and why the formula should be used in solving the problem. This teaching approach is aligned with what Schroeder and Lester (1989) warned as a narrow interpretation of teaching mathematics for problem solving. Although Zoe included a modeling standard, she in fact provided "an opportunity to 'apply' 
recently learned concepts and skills to the solution of real-world problems" (Schroeder \& Lester, 1989, p. 34). As Schroeder and Lester stated, this instructional approach is common in textbooks, and most MPSTs likely learned mathematics through this approach in their own mathematics classes.

Ava also included a modeling standard in one of her student teaching lesson plans: "Graph linear

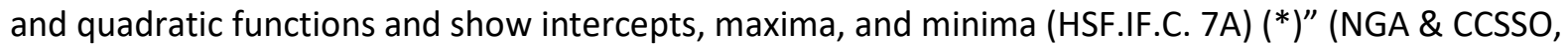
2010). She planned to introduce students to a parabola as the graph of a quadratic function, guide them to "identify the axis of symmetry, vertex, minimum or maximum, and zeros of a parabola," and to "describe the transformation or translation of a parabola based on the standard form of a quadratic function." The supervisor's observation of the lesson provided a summary of how this lesson was enacted in the classroom.

Ava launched the lesson by having students watch a short video about launching pumpkins then asking them to draw the trajectory of the pumpkin in flight. Students compared their representations and discussed the differences with other students, then drew the axis of symmetry, along with the axes of a coordinate plane so that their drawings looked like parabolas graphed on a grid...Students then summarized the way the parabola is reflected, stretched, or shifted by those value changes.

According to the supervisor's report and Ava's reflection, students learned new mathematical concepts, such as the definition and transformation of a parabola. They discussed constraints (e.g., air resistance, wind) that could affect the trajectory of the pumpkin. Students also created a model using a graphical representation and interpreted the results of the mathematics. Ava reported students enjoyed seeing how the real-world context could be connected to mathematics:

they had a lot of additional comments, such as how air resistance and wind would affect the trajectory and distance of the pumpkin. I let them discuss this a little because I liked that they were really thinking about the problem. I enjoyed bringing an outside subject into math, and I think they enjoyed it too. Students were very good at describing the differences between graphs.

Again, this task enactment may not align with how researchers define a modeling task; however, students learned important mathematical concepts, processes, and skills by connecting the mathematics 
with a real-life context through Ava's implementation. Students discussed the constraints, drew the trajectory, compared their representations, learned a new mathematical concept from the context, and used the concept to solve problems. Ava's instructional approach is closer to teaching mathematics via problem solving (Schroeder \& Lester, 1989) in that students engaged with the concrete (e.g., a realworld situation showing the trajectory of the pumpkin) and applied it to the abstract (e.g., quadratic functions).

\section{Discussion}

Previous researchers' work described in our theoretical framework section was useful in our examination of M-PSTs' ways of interpreting and incorporating mathematical modeling standards. We found that one way of interpreting mathematical modeling standards was connected to the definitions, choice of problems, and enactments (see Figure 1).

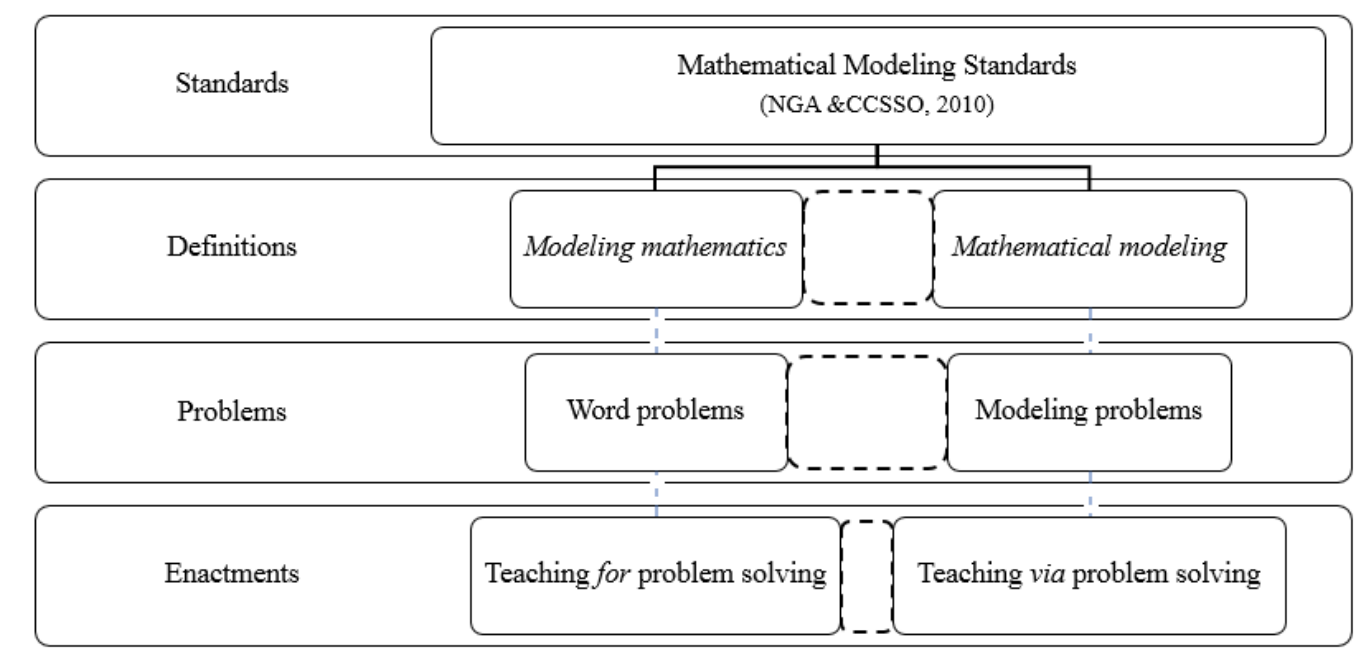

Figure 1. Potential adoption of mathematical modeling standards

Although the M-PSTs read the same standards (e.g., SMP: Model with Mathematics), their interpretations varied based on their conceptions of modeling mathematics vs. mathematical modeling (Cirillo et al., 2016). Most of their definitions evolved after experiencing one MEA and searching for 
modeling problems in textbooks; however, these experiences with mathematical modeling did not seem to result in the use of mathematical modeling in the teaching opportunities. In fact, when we were seeking evidence of their use of modeling standards from the three consecutive courses, we found only two M-PSTs who consistently used CCSSM mathematical modeling standards. While Zoe used several word problems to address CCSSM modeling standards, Ava used authentic real-life problems that are close to modeling problems (e.g., Blum \& Niss, 1991; Schukajlow et al., 2012). Although Ava's problems were not aligned with all of the principles of designing modeling problems (e.g., Lesh et al., 2000; Galbraith, 2007), her lessons included a spectrum of real-life problems that were located in the area between word problems and modeling problems, shown in Figure 1. We believe that many more problem types may fit in that middle area.

Another interesting aspect that Ava showed in her problems was that she noticed the same mathematical structure or model for different problem-solving situations (Simon, 1995). This recognition seems to be close to the implementational approach, teaching via problem solving (Schroeder \& Lester, 1989). Instead of teaching for problem solving, in which a teacher aimed for students to learn about new mathematical concepts and apply them to solve word problems, Ava began with a real-life problemsolving situation and guided students to see the mathematical structure or model embedded in the situation. Again, Ava's approach is not completely aligned with teaching via problem solving. We think that there could be diverse approaches to implementations that fit into the middle space between teaching for problem solving and teaching via problem solving, shown in Figure 1. Our goal is to move them from the boxes on the left, where most of them begin because of their past experiences, to the middle, then perhaps to the right eventually for their definitions, problems, and enactments for mathematical modeling. 


\section{Reflections as Mathematics Teacher Educators}

As we analyzed our M-PSTs' experiences and perspectives, we also reflected on our own

instruction. We realized most M-PSTs' understanding of mathematical modeling did not result in their enactments of modeling standards. This realization led us to change our future instruction in several ways: (1) giving careful attention to engaging M-PSTs with authentic problem solving as we aimed to teach mathematics via problem solving throughout the courses, (2) being explicit about the differences between modeling mathematics and mathematical modeling, word problems and modeling problems, and teaching for and via problem solving, (3) working in teachers' classrooms to co-plan, co-teach, and co-implement modeling lessons (e.g., Jung \& Brady, 2015), and (4) asking M-PSTs not only to solve modeling problems, but also to pose modeling problems as they critically analyze the standards, contexts, and mathematical structures embedded in the situations (e.g., I, Jung, \& Son, 2017). We also plan to engage M-PSTs with activities in which they analyze modeling problems posed by others using both sets of design principles (i.e., Lesh et al., 2000; Galbraith, 2007) and discuss whether students learn mathematics for or via problem solving (Schroeder \& Lester, 1989) as they watch video clips of classroom implementation of mathematical modeling.

We learned how difficult it is to implement mathematical modeling as we saw several aspects of knowledge that M-PSTs needed to have related to the standards, definitions, modeling problems, and enactments in authentic problem-solving situations. The M-PSTs' interpretations and enactments of CCSSM mathematical modeling standards throughout the three courses suggested the challenges inherent in designing courses in which we address multiple aspects of NCTM's vision for teaching and learning mathematics. We recognized that we need to use more effective and efficient ways to connect these aspects - e.g., solving mathematical modeling problems with equity issues in mind (Cirillo, Bartell, \& Wager, 2016), incorporating formative and summative assessments of mathematical modeling problems, using technology in conjunction with mathematical modeling, and connecting these 
approaches with utilizing recently released materials about mathematical modeling, such as the GAIMME report (Garfunkel et al., 2016). When we take our past teaching and research experience into consideration, we can make significant changes in our own instruction that may result in our students enhanced implementation of mathematical modeling. 


\section{References}

Blum, W. (2011). Can modelling be taught and learnt? Some answers from empirical research. In G.

Kaiser, W. Blum, R. Borromeo Ferri, \& G. Stillman (Eds.), Trends in teaching and learning mathematical modelling (pp. 15 -30). New York: Springer

Blum, W., \& Niss, M. (1991). Applied mathematical problem solving, modelling, applications, and links to other subjects-State, trends, and issues in mathematics instruction. Educational Studies in Mathematics, 22, 37-68.

Bostic, J., \& Matney, G. T. (2014). Role-playing the standards for mathematical practice: A professional development tool. Journal for Mathematics Education Leadership, 15(2), 3-10.

Cirillo, M., Bartell, T.G., \& Wager, A.A. (2016). Teaching mathematics for social justice through mathematical modeling. In C. R. Hirsch \& A. R. McDuffie (Eds.), Annual perspectives in mathematics education 2016: Mathematical modeling and modeling mathematics (pp. 87-95). VA: National Council of Teachers of Mathematics.

Cirillo, M., Pelesko, J. A., Felton-Koestler, M. D., \& Rubel, L. (2016). Perspectives on modeling in school mathematics. In C. R. Hirsch \& A. R. McDuffie (Eds.), Annual perspectives in mathematics education 2016: Mathematical modeling and modeling mathematics (pp. 3-16). VA: National Council of Teachers of Mathematics.

Doerr, H. M. (2016). Designing sequences of model development tasks. In C. R. Hirsch \& A. R. McDuffie (Eds.), Annual perspectives in mathematics education 2016: Mathematical modeling and modeling mathematics (pp. 197-205). VA: National Council of Teachers of Mathematics. 
Galbraith, P. (2007). Dreaming a "possible dream": More windmills to conquer. In C. Haines, P. Galbraith, W. Blum, \& S. Khan (Eds.), Mathematical modelling: Education, engineering and economics (pp. 44-62). Chichester, UK: Horwood.

Gamow, G. (2012). One Two Three... Infinity: Facts and Speculations of Science. Rockland, MA: Courier Publications.

Garfunkel, Sol, et al. (2016). Guidelines for Assessment and Instruction in Mathematical Modeling Education. Boston/Philadelphia: Consortium for Mathematics and Its Applications/Society for Industrial and Applied Mathematics. Retrieved from http://www.siam.org/reports/gaimmefull_color_for_online_viewing.pdf

Gravemeijer, K. (2004). Emergent modeling as a precursor to mathematical modeling. In H.-W. Henn \& W. Blum (Eds.), ICMI Study 14: Applications and modelling in mathematics education, preconference volume (pp. 97-102). Dortmund: Universität Dortmund.

Hiebert, J., Morris, A. K., Berk, D., \& Jansen, A. (2007). Preparing teachers to learn from teaching. Journal of Teacher Education, 58(1), 47-61.

I, J., Jung, H., \& Son, J. (2017). Developing criteria to design and assess mathematical modeling problems: from problems to social justice. In Galindo, E., \& Newton, J., (Eds.). Proceedings of the $39^{\text {th }}$ annual meeting of the North American Chapter of the International Group for the Psychology of Mathematics Education. Indianapolis, IN: Hoosier Association of Mathematics Teacher Educators.

Jung, H., \& Brady, C.E. (2015). Roles of a teacher and researcher during in-situ professional development around the implementation of modeling activities. Journal of Mathematics Teacher Education. 18(6), 1-19. 
Jung, H., Mintos, A., \& Newton, J. (2015). Preparing secondary mathematics teachers: Focus on modeling in algebra. The Mathematics Educator. 24(1), 44-71.

Lesh, R., \& Harel, G. (2003). Problem solving, modeling, and local conceptual development. Mathematical thinking and learning, 5(2-3), 157-189.

Lesh, R., Hoover, M., Hole, B., Kelly, A., \& Post, T. (2000). Principles for developing thought-revealing activities for students and teachers. In A. Kelly \& R. Lesh (Eds.). Handbook of research design in mathematics and science education (pp. 591-646). Mahwah, NJ: Lawrence Erlbaum Associates, Inc.

Lesh, R., \& Lehrer, R. (2003). Models and modeling perspectives on the development of students and teachers. Mathematical thinking and learning, 5(2-3), 109-129.

Lester, F. K., \& Kehle, P. E. (2003). From problem solving to modeling: The evolution of thinking about research on complex mathematical activity. In R. Lesh \& H.M., Doerr (Eds.). Beyond constructivism: Models and modeling perspectives on mathematics problem solving, learning, and teaching, 501-518.

National Council of Teachers of Mathematics. (1980). An agenda for action. Reston, VA: Author.

National Council of Teachers of Mathematics. (1989). Curriculum and evaluation standards for school mathematics. Reston, VA: Author.

National Council of Teachers of Mathematics. (1991). Professional standards for teaching mathematics. Reston, VA: Author.

National Council of Teachers of Mathematics. (2000). Principles and standards for school mathematics (Vol. 1). Reston, VA: National Council of Teachers of Mathematics 
National Council of Teachers of Mathematics (2009). Focus in high school mathematics: Reasoning and sense making in algebra. Reston, VA: National Council of Teachers of Mathematics.

National Governor's Association Center for Best Practices \& Council of Chief State School Officers. (2010). Common core state standards for mathematics. Washington, DC: Authors.

Phillips, E. D. (2016). Supporting teachers' learning about mathematical modeling. In C. R. Hirsch \& A. R. McDuffie (Eds.), Annual perspectives in mathematics education 2016: Mathematical modeling and modeling mathematics (pp. 249-251). VA: National Council of Teachers of Mathematics.

Schroeder, T. L. \& Lester, F. K. (1989). Developing understanding in mathematics via problem solving. In P. R. Trafton \& A. P. Shulte (Eds.), New directions for elementary school mathematics (pp. 31 42). Reston, VA: National Council of Teachers of Mathematics.

Schukajlow, S., Leiss, D., Pekrun, R., Blum, W., Müller, M., \& Messner, R. (2012). Teaching methods for modelling problems and students' task-specific enjoyment, value, interest and self-efficacy expectations. Educational Studies in Mathematics, 79(2), 215-237.

Simon, M. A. (1995). Reconstructing mathematics pedagogy from a constructivist perspective. Journal for Research in Mathematics Education, 26(2), 114-145.

Swokowski, E., \& Cole, J. (2011). Algebra and Trigonometry with Analytic Geometry. Boston, MA: Cengage Learning.

Yin, R. K. (Ed.). (2014). Case study research: Design and methods. Beverly Hills, CA: Sage Publications.

Zbiek, R. M. (2016). Supporting teachers' development as modelers and teachers of modelers. In C. R. Hirsch \& A. R. McDuffie (Eds.), Annual perspectives in mathematics education 2016: Mathematical modeling and modeling mathematics (pp. 263-271). VA: National Council of Teachers of Mathematics. 